\title{
A New Mathematical Model For Heat Radius of Cyclic Superheated Steam Stimulation with Horizontal Wellbore
}

\author{
Congge He $\mathbb{D}^{\mathbb{C}}$, Anzhu Xu, Zifei Fan, Lun Zhao, and Bing Bo \\ Research Institute of Petroleum Exploration \& Development, PetroChina, 20 Xueyuan Road, Haidian, Beijing 100083, China \\ Correspondence should be addressed to Congge He; hecongge1988@163.com
}

Received 8 March 2018; Accepted 3 May 2018; Published 31 May 2018

Academic Editor: Sandro Longo

Copyright (c) 2018 Congge He et al. This is an open access article distributed under the Creative Commons Attribution License, which permits unrestricted use, distribution, and reproduction in any medium, provided the original work is properly cited.

\begin{abstract}
When superheated steam flows along the horizontal wellbore, it may change to saturated steam at some point of the wellbore. In this paper, to accurately predict the heat radius of cyclic superheated steam stimulation with horizontal wellbore, the distribution of thermophysical properties of superheated steam along the horizontal wellbore is considered. The heating process is divided into 4 stages for superheated steam and 3 stages for saturated steam when the phase change undergoes in the wellbore. On this basis, the mathematical model for heat radius of cyclic superheated steam stimulation with horizontal wellbore was established according to energy conservation principle and Laplace transformation method. The calculation result of the new mathematical model is in good agreement with that of the numerical simulation (CMG STARS) for the same parameters from a specific heavy oil reservoir, which verified the correctness of the new mathematical model. The effect of degree of superheat and the cycle of stimulation are analyzed in detail after the new mathematical model is validated. The results show that the heat radius of superheated zone, steam zone, and hot fluid zone all decrease with horizontal well length and increase with the cycle of stimulation. The higher the degree of superheat is, the farther from the heel of the horizontal wellbore the phase change undergoes. Besides, the radius of superheated zone, steam zone, and hot fluid zone increases with the degree of superheat, but the value increases little at steam zone and hot fluid zone.
\end{abstract}

\section{Introduction}

By far, steam injection is the most extensively adopted enhanced oil recovery process in heavy oil resources development because the viscosity of heavy oil reduces rapidly with temperature and therefore the flowing ability of heavy oil is significantly improved [1-3]. Compared with vertical well, horizontal well has the characteristic of larger contact area with the formation, greater steam injection capacity, and higher productivity [4-9]. Superheated steam, obtained by continually heating the saturated steam above its saturation temperature, is a new technology for the recovery of heavy oil reservoirs for the reason that superheated steam has higher temperature and larger enthalpy [10-14]. Cyclic superheated steam stimulation with horizontal wellbore can fully exert the advantages of horizontal well and superheated steam, and therefore it is an important method for developing heavy oil reservoirs, especially thin reservoirs.

The calculation of heat radius during cyclic steam stimulation is the base for evaluation of productivity and forecast of dynamic performance. Marx-Langenheim [15] and Willman [16] have done pioneering work in establishing mathematical models to calculate the heat radius of cyclic steam stimulation with vertical well according to energy conservation principle. On this basis, Li Chunlan [17, 18] and Zhou Tiyao [19] established mathematical models for heat radius with the consideration of the nonisothermal distribution of the formation temperature in the heating area. Van Lookeren analyzed the effect of steam override and built a model for steam zone front. Lai Lingbin $[20,21]$ established steam injection model based on Van Lookeren's steam override theory. The heat radius of steam stimulation with horizontal wellbore is different from that with vertical well. Ni Xuefeng [22] and Liu Chunze [23] derived calculating models of heat radius along horizontal wellbore according to the fact that horizontal wellbores are different from vertical wellbore in terms of heating process and mechanism.

The authors and their team have done some research on the mathematical model of steam soaking heat radius and productivity prediction for heavy oil reservoirs [24], the effect 
of steam override [25], mechanism of heavy oil recovery by cyclic superheated steam stimulation [26], factors affecting the performance of cyclic superheated steam stimulation $[27,28]$, the mathematical model of the heat radius for the superheated steam stimulation with vertical well [29], and the mathematical model to calculate thermophysical parameters of horizontal wellbore in the superheated steam injection [30]. Based on previous research, the authors begin to predict the heat radius of cyclic superheated steam stimulation with horizontal wellbore that is applied in K oilfield, Kazakhstan. The heat radius of superheated steam stimulation with horizontal wellbore is different from that with vertical well. The difference is mainly manifested in two aspects. Firstly, when the superheated steam flows along the horizontal wellbore, the mass flow rate, temperature, and steam quality change over the horizontal well length. Secondly, as superheated steam flows along the horizontal wellbore, it may change to saturated steam at some point of the wellbore.

The main purpose of this paper is to establish a mathematical model for heat radius of cyclic superheated steam stimulation with horizontal wellbore. In this work, in order to achieve that goal, the distribution of thermophysical properties of superheated steam along the horizontal wellbore is considered. The heating process is divided into 4 stages for superheated steam and 3 stages for saturated steam when phase change undergoes in the wellbore. On this basis, the mathematical model for heat radius of cyclic superheated steam stimulation with horizontal wellbore was established according to energy conservation principle and Laplace transformation method. Finally, after the new proposed mathematical model is validated by comparison with the results of numerical simulation (CMG STARS) for the same parameters from a specific heavy oil reservoir, the effect of degree of superheat and the cycle of stimulation are analyzed in detail.

\section{Mathematical Model}

2.1. Basic Assumptions of the Mathematical Model. The mathematical model is subject to the following basic assumptions:

(1) The horizontal wellbore is located in the center of the formation and the steam override effect is ignored due to thin formation thickness.

(2) When the superheated steam flows along the wellbore, it may undergo phase change. The superheated steam may change to saturated steam at some point of the wellbore as Figure 1 shows.

(3) Before phase change occurs, the heating process is divided into four stages and three zones are formed in the heating area: superheated zone, steam zone, and hot fluid zone. After phase change occurs, the heating process is divided into three stages and two zones remain in the heating area: steam zone and hot fluid zone (as shown in Figure 2).

(4) The temperature of superheated zone equals the arithmetic mean value of superheated steam temperature and saturated steam temperature. The temperature of

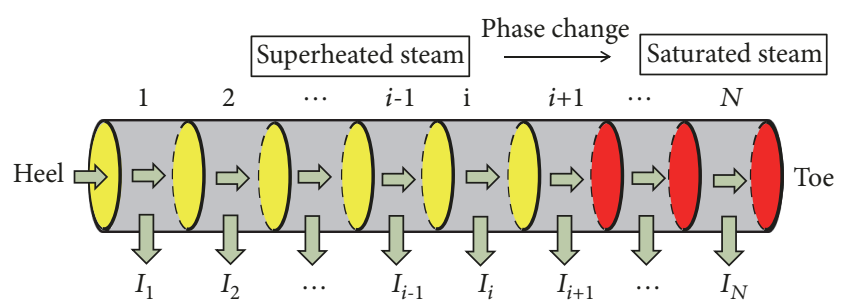

FIGURE 1: Division of the horizontal wellbore during superheated steam injection.

steam zone equals the saturated steam temperature. The temperature of hot fluid zone equals the arithmetic mean value of saturated steam temperature and initial reservoir temperature (as shown in Figure 3).

(5) The formation temperature is assumed to be the initial reservoir temperature at each cycle of steam injection, and the remainder heat is added to the next cycle of steam injection.

2.2. The Derivation of the Mathematical Model. When the superheated steam flows along the horizontal wellbore, its mass flow rate, temperature, and steam quality change over the horizontal well length. Consequently, the heat radius changes along the horizontal wellbore. In order to accurately calculate the heat radius of horizontal wellbore, the distribution of those thermophysical parameters along the horizontal wellbore first need to be determined. Zifei Fan et al. [30] proposed a widely used mathematical model to calculate thermophysical parameters of horizontal wellbore in the superheated steam injection. Based on Zifei Fan's model, the mathematical model for heat radius of cyclic superheated steam stimulation with horizontal well is derived. It is assumed that the $i$-th segment of horizontal wellbore, which is taken as calculation example, has not yet undergone phase change. As the derivation process of the saturated steam is similar to the superheated steam after phase change occurs, this article only derives the heat radius of superheated steam.

2.2.1. Stage 1. At stage 1, all injected heat is used to heat the reservoir because the frontier of hot fluid zone has no yet reached the boundary (as shown in Figure 2(a)). Non-heat losses to the boundary at this stage. Therefore, based on the energy conservation principle for superheated zone, we have

$$
H_{\mathrm{sh} i} \mathrm{~d} t=M_{\mathrm{R}} \Delta L\left(\overline{T_{\mathrm{sh} i}}-T_{\mathrm{r}}\right) \mathrm{d} A_{\mathrm{sh} i}
$$

where $H_{\text {shi }}$ is the superheated steam zone heat injection rate at the $i$-th segment, $H_{\mathrm{sh} i}=I_{i} \rho_{i}\left(h_{\mathrm{sh} i}-h_{\mathrm{s} i}\right)+E_{\mathrm{rsh} i}, I_{i}$ is the volumetric outflow rate at the $i$-th segment, $\rho_{i}$ is the steam density at the $i$-th segment, $E_{\mathrm{rsh} i}$ is the previous cycle remainder heat of superheated zone at the $i$-th segment, $h_{\text {shi }}$ and $h_{\text {si }}$ are the specific enthalpy of superheated steam and the specific enthalpy of saturated steam at the $i$-th segment, respectively; $\Delta L$ is the segment length; $\overline{T_{\text {sh }}}$ is the superheated zone temperature, $\overline{T_{\mathrm{sh} i}}=\left(T_{\mathrm{sh} i}+T_{\mathrm{si}}\right) / 2, T_{\mathrm{sh} i}$ and $T_{\text {si }}$ are superheated steam temperature and saturated steam, respectively. $T_{\mathrm{r}}$ is the initial reservoir temperature; $A_{\mathrm{sh} i}$ is 

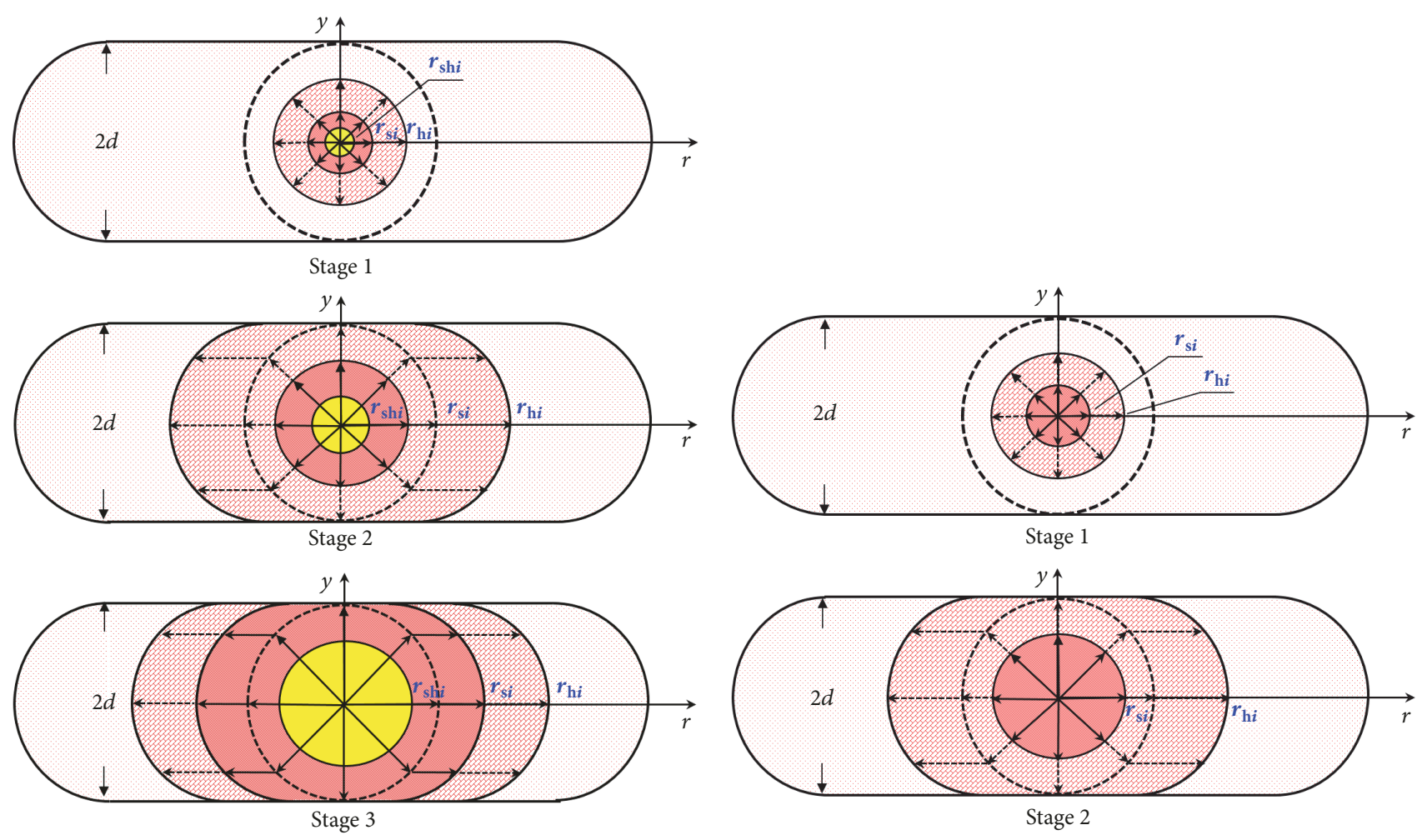

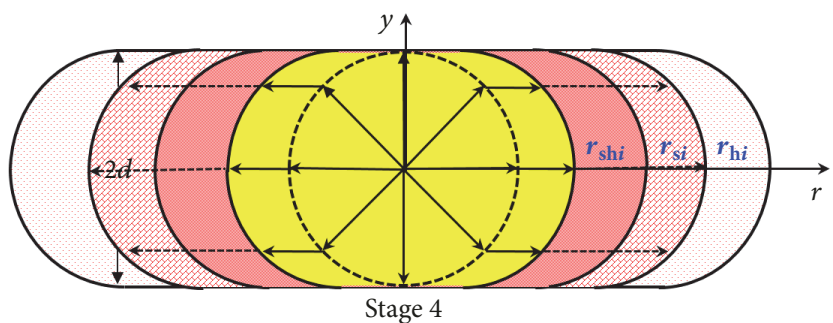

Superheatd zone Steam zone
W Hot fluid zone

(a) Superheated steam

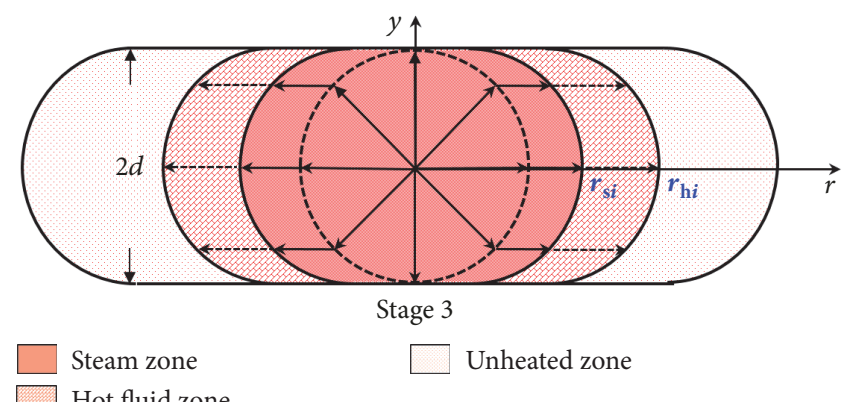

(b) Saturated steam

FIGURE 2: Schematic of horizontal well heating process.

the superheated steam zone area at the $i$-th segment; $t$ is the injection time; $M_{\mathrm{R}}$ is the reservoir heat capacity.

For supposes that the steam override effect is ignored due to thin formation thickness, the heat area is round shape. Therefore, by integration of (1), the radius of superheated steam zone at the $i$-th segment, $r_{\text {shi }}$, can be expressed as

$$
r_{\mathrm{sh} i}=\sqrt{\frac{H_{\mathrm{sh} i} t}{\pi M_{\mathrm{R}} \Delta L\left(\overline{T_{\mathrm{sh} i}}-T_{\mathrm{r}}\right)}}
$$

Similarly, the radius of steam zone and hot fluid zone at the $i$-th segment can be expressed as

$$
\begin{aligned}
& r_{\mathrm{s} i}=\sqrt{\frac{t}{\pi M_{\mathrm{R}} \Delta L}\left(\frac{H_{\mathrm{s} i}}{T_{\mathrm{s} i}-T_{\mathrm{r}}}+\frac{H_{\mathrm{sh} i}}{\overline{T_{\mathrm{sh} i}}-T_{\mathrm{r}}}\right)} \\
& r_{\mathrm{h} i}=\sqrt{\frac{t}{\pi M_{\mathrm{R}} \Delta L}\left(\frac{H_{\mathrm{w} i}}{\overline{T_{\mathrm{h} i}}-T_{\mathrm{r}}}+\frac{H_{\mathrm{s} i}}{T_{\mathrm{si}}-T_{\mathrm{r}}}+\frac{H_{\mathrm{sh} i}}{\overline{T_{\mathrm{sh} i}}-T_{\mathrm{r}}}\right)}
\end{aligned}
$$

where $r_{s i}$ and $r_{\mathrm{h} i}$ are the radius of steam zone and hot fluid zone at the $i$-th segment, respectively; $H_{s i}$ is the steam zone heat injection rate at the $i$-th segment, $H_{\mathrm{s} i}=I_{i} \rho_{i} L_{\mathrm{v} i}+E_{\mathrm{rs} i}, L_{\mathrm{v} i}$ is the steam latent heat at the $i$-th segment, $E_{\mathrm{rs} i}$ is the previous cycle remainder heat of steam zone at the $i$-th segment; $H_{\mathrm{w} i}$ is the hot fluid zone heat injection rate at the $i$-th segment, $H_{\mathrm{w} i}=I_{i} \rho_{i}\left(h_{\mathrm{wsi}}-h_{\mathrm{wri}}\right)+E_{\mathrm{rw} i}, h_{\mathrm{ws} i}$ and $h_{\mathrm{wri}}$ are the water specific enthalpy of the steam temperature and the water specific enthalpy of the reservoir temperature at the $i$-th segment, respectively, $E_{\mathrm{rw} i}$ is the previous cycle remainder heat of hot fluid zone at the $i$-th segment; $\overline{T_{\mathrm{h} i}}$ is the hot fluid zone temperature, $\overline{T_{\mathrm{hi}}}=\left(T_{\mathrm{si}}+T_{\mathrm{r}}\right) / 2$.

The times that the frontier of hot fluid zone reaches the boundary, the frontier of steam zone reaches the boundary, and the frontier of superheated zone reaches the boundary are defined as the first critical time, the second critical time, and the third critical time, respectively. Based on the definition and (2) (4), the first critical time, the second critical time, 


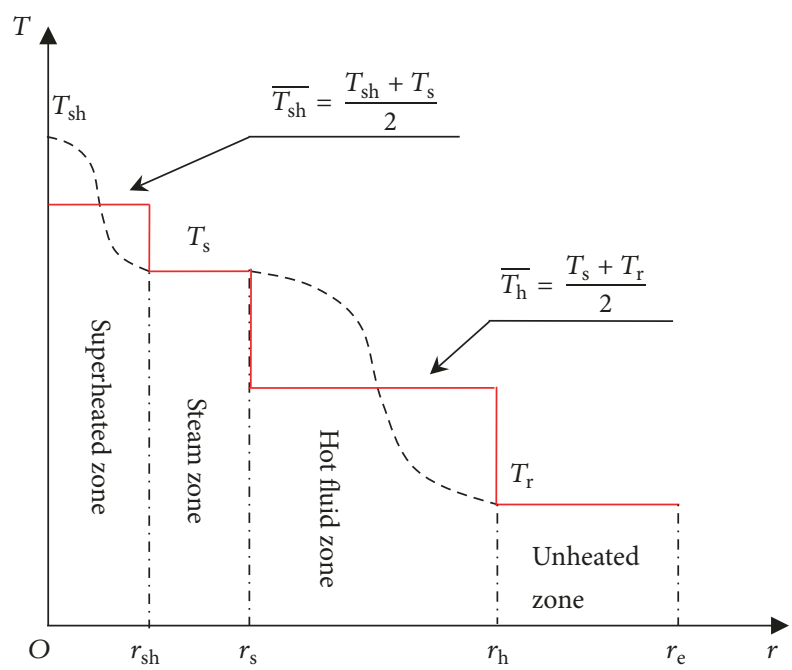

FIGURE 3: Temperature distribution of formation in the superheated steam injection process.

and the third critical time at the $i$-th segment can be written as

$$
\begin{aligned}
& t_{\mathrm{c} 1 i}=\pi M_{\mathrm{R}} \Delta L d^{2}\left(\frac{H_{\mathrm{h} i}}{\overline{T_{\mathrm{h} i}}-T_{\mathrm{r}}}+\frac{H_{\mathrm{s} i}}{T_{\mathrm{s} i}-T_{\mathrm{r}}}+\frac{H_{\mathrm{sh} i}}{\overline{T_{\mathrm{sh} i}}-T_{\mathrm{r}}}\right)^{-1} \\
& t_{\mathrm{c} 2 i}=\pi M_{\mathrm{R}} \Delta L d^{2}\left(\frac{H_{\mathrm{s} i}}{T_{\mathrm{s} i}-T_{\mathrm{r}}}+\frac{H_{\mathrm{sh} i}}{\bar{T}_{\mathrm{sh} i}-T_{\mathrm{r}}}\right)^{-1} \\
& t_{\mathrm{c} 3 i}=\pi M_{\mathrm{R}} \Delta L d^{2} \frac{\overline{T_{\mathrm{sh} i}}-T_{\mathrm{r}}}{H_{\mathrm{sh} i}}
\end{aligned}
$$

where $t_{\mathrm{c} 1 i}, t_{\mathrm{c} 2 i}$ and $t_{\mathrm{c} 3 i}$ are the first critical time at the $i$-th segment, the second critical time at the $i$-th segment, the third critical time at the $i$-th segment, respectively. $d$ is the half of reservoir thickness.

2.2.2. Stage 2. At stage 2, the frontier of hot fluid zone reaches the boundary but not the frontier of steam zone and superheated zone as shown in Figure 2(a), namely, $t_{\mathrm{cli}} \leq t<$ $t_{\mathrm{c} 2 i}$. Due to non-heat loss to the boundary at the steam zone and the superheated zone, the radius of superheated zone and steam zone at the $i$-th segment are still calculated by (2) and (3), respectively. For hot fluid zone, one part of the injected heat is used to heat the formation and other part losses to the boundary. Therefore, the heat balance of hot fluid zone can be written as [31]

$$
\begin{aligned}
H_{\mathrm{w} i}= & \frac{2}{\sqrt{\pi \alpha_{\mathrm{s}}}} \int_{0}^{B_{\mathrm{h} i}} \frac{\lambda_{\mathrm{s}}\left(\overline{T_{\mathrm{h} i}}-T_{\mathrm{r}}\right)}{\sqrt{t-t_{\mathrm{c} 1 i}}} \mathrm{~d} B_{\mathrm{h} i} \\
& +M_{\mathrm{R}} \Delta L\left(\overline{T_{\mathrm{h} i}}-T_{\mathrm{r}}\right) \frac{\mathrm{d} A_{\mathrm{h} 2 i}}{\mathrm{~d} t}
\end{aligned}
$$

where $B_{\mathrm{h} i}$ is the contact area of boundary and hot fluid zone at the $i$-th segment; $\lambda_{\mathrm{s}}$ is the thermal conduction coefficient of the boundary; $\alpha_{\mathrm{s}}$ is thermal diffusivity of the boundary;
$A_{\mathrm{h} 2 i}=A_{\mathrm{h} i}-A_{\mathrm{h} 1 i}$, and $A_{\mathrm{h} 1 i}$ is the hot fluid zone area at the $i$-th segment as the frontier of hot fluid zone reaches the boundary, $A_{\mathrm{h} 1 i}=\pi\left(d^{2}-r_{\mathrm{si}}{ }^{2}\right), A_{\mathrm{h} i}$ is the hot fluid zone area at the $i$-th segment.

The left side in (8) represents the heat injection rate, the first term of the right side in (8) represents the heat loss rate to the boundary, and the second term of the right side in (8) represents heat growth rate of hot fluid zone.

Assuming that heat transfers linearly in the formation after the frontier of hot fluid zone arrives the boundary, therefore, $\mathrm{d} B_{\mathrm{h} i}$ can be expressed as $\mathrm{d} B_{\mathrm{h} i}=(\Delta L / \pi d) \mathrm{d} A_{\mathrm{h} 2 i}$. Hence, (8) can be rewritten as

$$
\begin{aligned}
H_{\mathrm{w} i}= & \int_{0}^{t-t_{\mathrm{cl} i}} \frac{2 \lambda_{\mathrm{s}}\left(\overline{T_{\mathrm{h} i}}-T_{\mathrm{r}}\right)}{\sqrt{\pi \alpha_{\mathrm{s}}\left(t-t_{\mathrm{c} 1 i}-\delta\right)}} \frac{\Delta L}{\pi d} \frac{\mathrm{d} A_{\mathrm{h} 2 i}}{\mathrm{~d} \delta} \mathrm{d} \delta \\
& +M_{\mathrm{R}} \Delta L\left(\overline{T_{\mathrm{h} i}}-T_{\mathrm{r}}\right) \frac{\mathrm{d} A_{\mathrm{h} 2 i}}{\mathrm{~d} t}
\end{aligned}
$$

where $\delta$ is the instant at which the boundary becomes exposed to the hot fluid.

After Laplace transformation and inverse Laplace transformation for (9), we have

$$
\begin{aligned}
& A_{\mathrm{h} 2 i}=\frac{H_{\mathrm{w} i} M_{\mathrm{R}} \alpha_{\mathrm{s}}(\pi d)^{2}}{4 \lambda_{\mathrm{s}}^{2} \Delta L\left(\overline{T_{\mathrm{h} i}}-T_{\mathrm{r}}\right)}\left[\mathrm{e}^{b^{2}\left(t-t_{\mathrm{cli}}\right)} \operatorname{erfc}\left(b \sqrt{t-t_{\mathrm{cl} i}}\right)\right. \\
& \left.\quad+2 \sqrt{\frac{t-t_{\mathrm{c} 1 i}}{\pi}} b-1\right]
\end{aligned}
$$

where $b=2 \lambda_{\mathrm{s}} / \pi d M_{\mathrm{R}} \sqrt{\alpha_{\mathrm{s}}}$.

On account of $A_{\mathrm{h} 2 i}=2 \pi d\left(r_{\mathrm{h} i}-d\right)$, from (10), the radius of hot fluid zone at the $i$-th segment at stage 2 can be expressed as

$$
\begin{aligned}
r_{\mathrm{h} i} & =d \\
& +\frac{H_{\mathrm{wi} i} M_{\mathrm{R}} \alpha_{\mathrm{s}} \pi d}{8 \lambda_{\mathrm{s}}^{2} \Delta L\left(\overline{T_{\mathrm{h} i}}-T_{\mathrm{r}}\right)}\left[\mathrm{e}^{b^{2}\left(t-t_{\mathrm{cl} i}\right)} \operatorname{erfc}\left(b \sqrt{t-t_{\mathrm{cl} i}}\right)\right. \\
& \left.+2 \sqrt{\frac{t-t_{\mathrm{cl} i}}{\pi}} b-1\right]
\end{aligned}
$$

2.2.3. Stage 3. At stage 3, the frontiers of hot fluid zone and steam zone reach the boundary but not the frontier of superheated zone as shown in Figure 2(a), namely, $t_{\mathrm{c} 2 i} \leq t<$ $t_{\mathrm{c} 3 i}$. Due to non-heat loss to the boundary at the superheated zone, the radius of superheated zone at the $i$-th segment is still calculated by (2). For steam zone, the heat balance can be written as

$$
\begin{aligned}
H_{\mathrm{s} i}= & \frac{2}{\sqrt{\pi \alpha_{\mathrm{s}}}} \int_{0}^{A_{\mathrm{s} 2 i}} \frac{\lambda_{\mathrm{s}}\left(T_{\mathrm{s} i}-T_{\mathrm{r}}\right)}{\sqrt{t-t_{\mathrm{c} 2 i}}} \frac{\Delta L}{\pi d} \mathrm{~d} A_{\mathrm{s} 2 i} \\
& +M_{\mathrm{R}} \Delta L\left(T_{\mathrm{s} i}-T_{\mathrm{r}}\right) \frac{\mathrm{d} A_{\mathrm{s} 2 i}}{\mathrm{~d} t}
\end{aligned}
$$

where $A_{\mathrm{s} 2 i}=A_{\mathrm{si}}-\pi d^{2}$. 
After Laplace transformation and inverse Laplace transformation for (12), we have

$$
\begin{aligned}
& A_{\mathrm{s} 2 i}=\frac{H_{\mathrm{s} i} M_{\mathrm{R}} \alpha_{\mathrm{s}}(\pi d)^{2}}{4 \lambda_{\mathrm{s}}{ }^{2} \Delta L\left(T_{\mathrm{s} i}-T_{\mathrm{r}}\right)}\left[\mathrm{e}^{b^{2}\left(t-t_{\mathrm{c} 2 i}\right)} \operatorname{erfc}\left(b \sqrt{t-t_{\mathrm{c} 2 i}}\right)\right. \\
& \left.\quad+2 \sqrt{\frac{t-t_{\mathrm{c} 2 i}}{\pi}} b-1\right]
\end{aligned}
$$

On account of $A_{\mathrm{s} 2 i}=2 \pi d\left(r_{\mathrm{s} i}-d\right)$, from (13), the radius of steam zone at the $i$-th segment at stage 3 can be expressed as

$$
\begin{aligned}
r_{\mathrm{s} i} & =d \\
& +\frac{H_{\mathrm{s} i} M_{\mathrm{R}} \alpha_{\mathrm{s}} \pi d}{8 \lambda_{\mathrm{s}}^{2} \Delta L\left(T_{\mathrm{s} i}-T_{\mathrm{r}}\right)}\left[\mathrm{e}^{b^{2}\left(t-t_{\mathrm{c} 2 i}\right)} \operatorname{erfc}\left(b \sqrt{t-t_{\mathrm{c} 2 i}}\right)\right. \\
& \left.+2 \sqrt{\frac{t-t_{\mathrm{c} 2 i}}{\pi}} b-1\right]
\end{aligned}
$$

For hot fluid zone, the heat balance can be written as

$$
\begin{aligned}
H_{\mathrm{w} i}= & 2 \int_{0}^{A_{\mathrm{h} i}} \frac{\lambda_{\mathrm{s}}\left(\overline{T_{\mathrm{h} i}}-T_{\mathrm{r}}\right)}{\sqrt{\pi \alpha_{\mathrm{s}} t}} \frac{\Delta L}{\pi d} \mathrm{~d} A_{\mathrm{h} i} \\
& +M_{\mathrm{R}} \Delta L\left(\overline{T_{\mathrm{h} i}}-T_{\mathrm{r}}\right) \frac{\mathrm{d} A_{\mathrm{h} i}}{\mathrm{~d} t}
\end{aligned}
$$

After Laplace transformation and inverse Laplace transformation for (15), we have

$$
\begin{aligned}
& A_{\mathrm{h} i} \\
& \quad=\frac{H_{\mathrm{w} i} M_{\mathrm{R}} \alpha_{\mathrm{s}}(\pi d)^{2}}{4 \lambda_{\mathrm{s}}{ }^{2} \Delta L\left(\overline{T_{\mathrm{h} i}}-T_{\mathrm{r}}\right)}\left[\mathrm{e}^{b^{2} t} \operatorname{erfc}(b \sqrt{t})+2 \sqrt{\frac{t}{\pi}} b-1\right]
\end{aligned}
$$

On account of $A_{\mathrm{h} i}=2 \pi d\left(r_{\mathrm{h} i}-r_{\mathrm{si}}\right)$, from (16), the radius of hot fluid zone at the $i$-th segment at stage 3 can be expressed as

$$
\begin{aligned}
r_{\mathrm{h} i} & =d \\
& +\frac{M_{\mathrm{R}} \alpha_{\mathrm{s}} \pi d}{8 \lambda_{\mathrm{s}}{ }^{2} \Delta L}\left\{\frac { H _ { \mathrm { s } i } } { T _ { \mathrm { s } i } - T _ { \mathrm { r } } } \left[\mathrm{e}^{b^{2}\left(t-t_{\mathrm{c} 2 i}\right)} \operatorname{erfc}\left(b \sqrt{t-t_{\mathrm{c} 2 i}}\right)\right.\right. \\
& \left.+2 \sqrt{\frac{t-t_{\mathrm{c} 2 i}}{\pi}} b-1\right]+\frac{H_{\mathrm{w} i}}{\overline{T_{\mathrm{h} i}}-T_{\mathrm{r}}}\left[\mathrm{e}^{b^{2} t} \operatorname{erfc}(b \sqrt{t})\right. \\
& \left.\left.+2 \sqrt{\frac{t}{\pi}} b-1\right]\right\}
\end{aligned}
$$

2.2.4. Stage 4. At stage 4, the frontier of hot fluid zone, steam zone, and superheated zone all reach the boundary as shown in Figure 2(a), namely, $t>t_{\mathrm{c} 3 i}$. For superheated zone, the heat balance can be written as

$$
\begin{aligned}
H_{\mathrm{sh} i}= & \frac{2}{\sqrt{\pi \alpha_{\mathrm{s}}}} \int_{0}^{A_{\mathrm{sh} 2 i}} \frac{\lambda_{\mathrm{s}}\left(\overline{T_{\mathrm{sh} i}}-T_{\mathrm{r}}\right)}{\sqrt{t-t_{\mathrm{c} 3 i}}} \frac{\Delta L}{\pi d} \mathrm{~d} A_{\mathrm{sh} 2 i} \\
& +M_{\mathrm{R}} \Delta L\left(\overline{T_{\mathrm{sh} i}}-T_{\mathrm{r}}\right) \frac{\mathrm{d} A_{\mathrm{sh} 2 i}}{\mathrm{~d} t}
\end{aligned}
$$

where $A_{\mathrm{sh} 2 i}=A_{\mathrm{sh} i}-\pi d^{2}$.
After Laplace transformation and inverse Laplace transformation for (18), we have

$$
\begin{aligned}
& A_{\mathrm{sh} 2 i} \\
& \quad=\frac{H_{\mathrm{sh} i} M_{\mathrm{R}} \alpha_{\mathrm{s}}(\pi d)^{2}}{4 \lambda_{\mathrm{s}}{ }^{2} \Delta L\left(\overline{T_{\mathrm{sh} i}}-T_{\mathrm{r}}\right)}\left[\mathrm{e}^{b^{2}\left(t-t_{\mathrm{c} 3 i}\right)} \operatorname{erfc}\left(b \sqrt{t-t_{\mathrm{c} 3 i}}\right)\right. \\
& \left.\quad+2 \sqrt{\frac{t-t_{\mathrm{c} 3 i}}{\pi}} b-1\right]
\end{aligned}
$$

On account of $A_{\mathrm{sh} 2 i}=2 \pi d\left(r_{\mathrm{sh} i}-d\right)$, from (19), the radius of superheated zone at the $i$-th segment at stage 4 can be expressed as

$$
\begin{aligned}
r_{\mathrm{sh} i} & =d \\
& +\frac{H_{\mathrm{sh} i} M_{\mathrm{R}} \alpha_{\mathrm{s}} \pi d}{8 \pi \lambda_{\mathrm{s}}{ }^{2} \Delta L\left(\overline{T_{\mathrm{sh} i}}-T_{\mathrm{r}}\right)}\left[\mathrm{e}^{b^{2}\left(t-t_{\mathrm{c} 3 i}\right)} \operatorname{erfc}\left(b \sqrt{t-t_{\mathrm{c} 3 i}}\right)\right. \\
& \left.+2 \sqrt{\frac{t-t_{\mathrm{c} 3 i}}{\pi}} b-1\right]
\end{aligned}
$$

For steam zone, the heat balance can be written as

$$
\begin{aligned}
H_{s i}= & \frac{2}{\sqrt{\pi \alpha_{\mathrm{s}}}} \int_{0}^{A_{\mathrm{si}}} \frac{\lambda_{\mathrm{s}}\left(T_{\mathrm{si}}-T_{\mathrm{r}}\right)}{\sqrt{t}} \frac{\Delta L}{\pi d} \mathrm{~d} A_{\mathrm{si}} \\
& +M_{\mathrm{R}} \Delta L\left(T_{\mathrm{s} i}-T_{\mathrm{r}}\right) \frac{\mathrm{d} A_{\mathrm{s} i}}{\mathrm{~d} t}
\end{aligned}
$$

After Laplace transformation and inverse Laplace transformation for (21), the radius of steam zone at the $i$-th segment at stage 4 can be expressed as

$$
\begin{aligned}
r_{\mathrm{si}} & =r_{\mathrm{sh} i}+\frac{H_{\mathrm{si}} M_{\mathrm{R}} \alpha_{\mathrm{s}} \pi d}{8 \lambda_{\mathrm{s}}^{2} \Delta L\left(T_{\mathrm{s} i}-T_{\mathrm{r}}\right)}\left[\mathrm{e}^{b^{2} t} \operatorname{erfc}(b \sqrt{t})\right. \\
& \left.+2 \sqrt{\frac{t}{\pi}} b-1\right]
\end{aligned}
$$

The radius of hot fluid zone at the $i$-th segment at stage 4 can be calculated by (17).

\section{Calculation Steps of the Model}

Now, the model for heat radius of cyclic superheated steam stimulation with horizontal wellbore is set up. The main steps of calculating the heat radius are as follows:

(1) The whole horizontal wellbore is divided into $N$ segments as Figure 1 shows.

(2) The distribution of thermophysical parameters (mass flow rate, temperature, and steam quality) along the horizontal wellbore is calculated by adopting the method in reference [30]

(3) Judge the superheated steam whether it undergoes phase change. The first critical time, the second critical time, and the third critical time are estimated according to $=(5) \sim(7)$.

(4) Judge the stage of the heating process and then calculate the heat radius. 


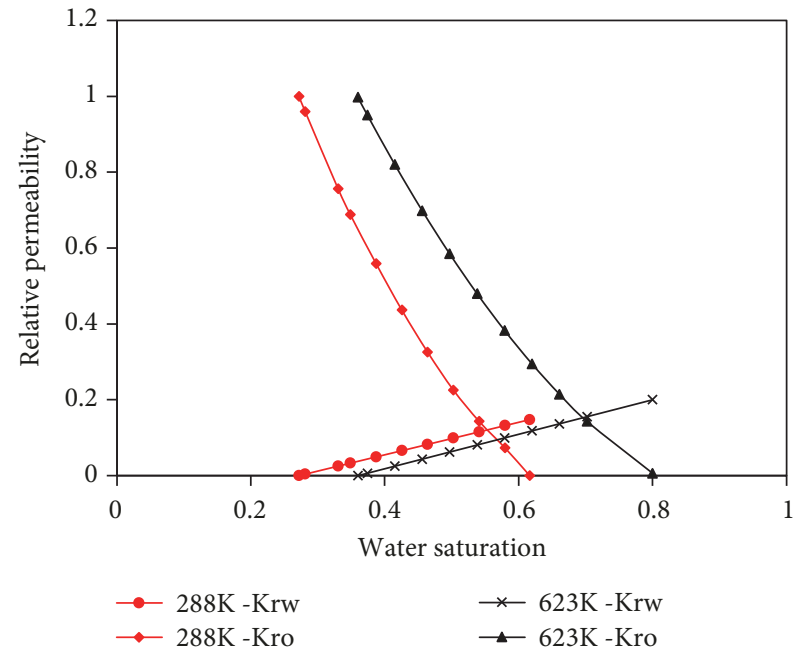

(a)

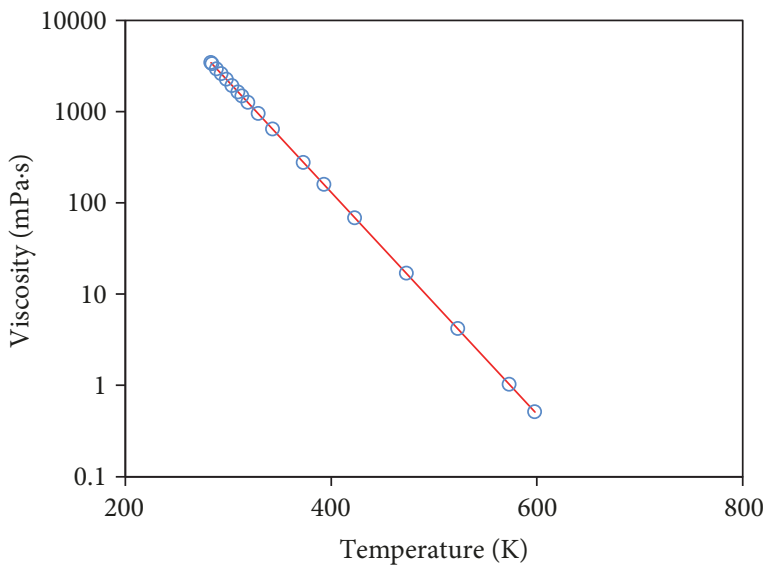

(b)

FIGURE 4: Curve of relative permeability (a) and viscosity-temperature relationship (b).

\section{Results and Discussion}

4.1. Model Verification. In order to verify this new mathematical model, we compare calculated results with reservoir numerical simulator (CMG STARS) simulated results. The gird size of CMG STARS numerical model is $50 \times 50 \times 15$ and the corresponding block dimensions are $4 \mathrm{~m}, 0.48 \mathrm{~m}$, and $0.4 \mathrm{~m}$. The reservoir physical properties and steam injection parameters are listed in Table 1 . The relative permeability curve and the viscosity-temperature relationship curve are shown in Figure 4.

Figure 5 clearly shows that the heat radius (the radius of hot fluid zone) calculated by our new model coincides with the CMG STARS simulated result along the horizontal wellbore. The maximum relative error is within $8.2 \%$, which is acceptable in engineering calculation. Figure 6 shows the comparison of heat radius between the new model and CMG STARS perpendicular to the horizontal wellbore at length of $100 \mathrm{~m}$. The heat radius calculated by our new model is highly in line with CMG STARS simulated result, which verifies the correctness of our new model.

\subsection{Influential Factors Analysis}

4.2.1. Effect of Degree of Superheat. Figure 7 shows the effect of the degree of superheat (the temperature difference between superheated steam and its saturated steam) on the profile of heat radius. It is easily found that the heat radius of superheated zone, steam zone, and hot fluid zone all decrease with horizontal well length. This is because the heat carried by injected fluid decreases with horizontal well length when the fluid flows along the horizontal wellbore since the heat and mass transfer into the reservoir. Moreover, the radius of superheated zone decreases to 0 when the superheated steam undergoes phase change. The higher the degree of superheat, the longer the distance between the phase change point and the heel of the horizontal wellbore. For instance, when the degree of superheat equals $303 \mathrm{~K}$, the radius of superheated

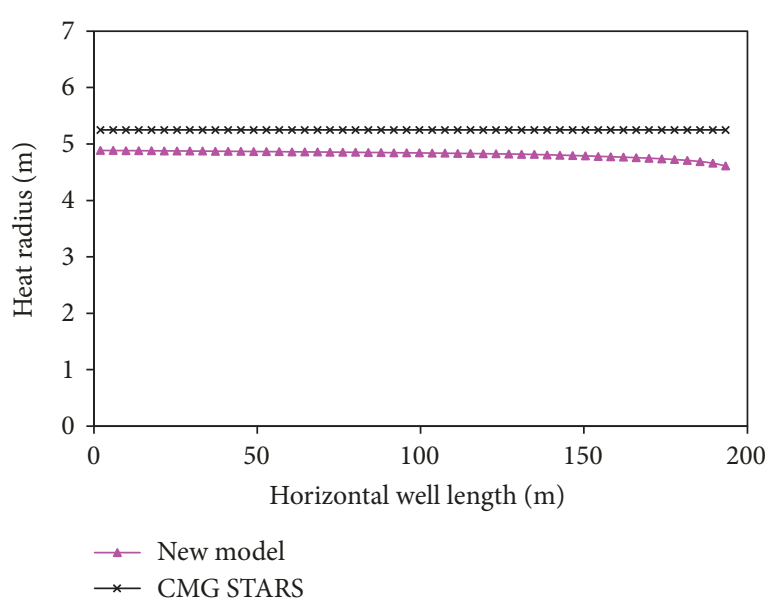

FIGURE 5: Comparisons of heat radius between the new model and CMG STARS along the horizontal wellbore.

zone is about $0.65 \mathrm{~m}$ at the heel of horizontal wellbore, and it decreases to 0 at horizontal well length of about $135 \mathrm{~m}$. When the degree of superheat increases from $303 \mathrm{~K}$ to $333 \mathrm{~K}$ and $363 \mathrm{~K}$, the phase change point at horizontal well length increases from $135 \mathrm{~m}$ to $170 \mathrm{~m}$ and $185 \mathrm{~m}$. In addition, the radius of superheated zone, steam zone, and hot fluid zone increases with the degree of superheat, but the value increases a little at steam zone and hot fluid zone. This is because the higher the degree of superheat, the higher the heat carried by injected fluid. Because the superheated steam can change the wettability of superheated zone and increase oil displacement efficiency and filtration ability of superheated zone, increasing the degree of superheat is an effective way to expand the superheated zone and consequently enhance oil recovery.

4.2.2. Effect of the Cycle of Stimulation. In the steam stimulation process, steam is injected into the reservoir for a period of weeks; the well is then allowed to flow back and 
TABLE 1: Parameters of reservoir physical properties and steam injection.

\begin{tabular}{lcc}
\hline Parameter & Unit & Value \\
\hline Thickness of reservoir & $\mathrm{m}$ & 6 \\
Initial reservoir temperature & $\mathrm{K}$ & 291.9 \\
Reservoir pressure & $\mathrm{Pa}$ & $2.38 \times 10^{6}$ \\
Porosity & - & 0.35 \\
Permeability & $\mu \mathrm{m}^{2}$ & - \\
Initial oil saturation & - & 0.42 \\
Volume factor of oil & - & 1.05 \\
Volume factor of water & $\mathrm{W} \cdot \mathrm{m}^{-1} \cdot \mathrm{K}^{-1}$ & 1.01 \\
Thermal conduction coefficient of boundary & $\mathrm{m} \cdot \mathrm{h}^{-1}$ & 1.73 \\
Thermal diffusivity of boundary & $\mathrm{J} \cdot \mathrm{m}^{-3} \cdot \mathrm{K}^{-1}$ & 0.00037 \\
Reservoir heat capacity & $\mathrm{m}$ & $2575 \times 10^{3}$ \\
Length of the horizontal wellbore & $\mathrm{t} / \mathrm{h}$ & 195 \\
Injection rate & $\mathrm{K}$ & 6.25 \\
Superheated steam temperature & $\mathrm{K}$ & 368.15 \\
Degree of superheat & $\mathrm{h}$ & 30 \\
Steam injection time & & 360 \\
\hline
\end{tabular}

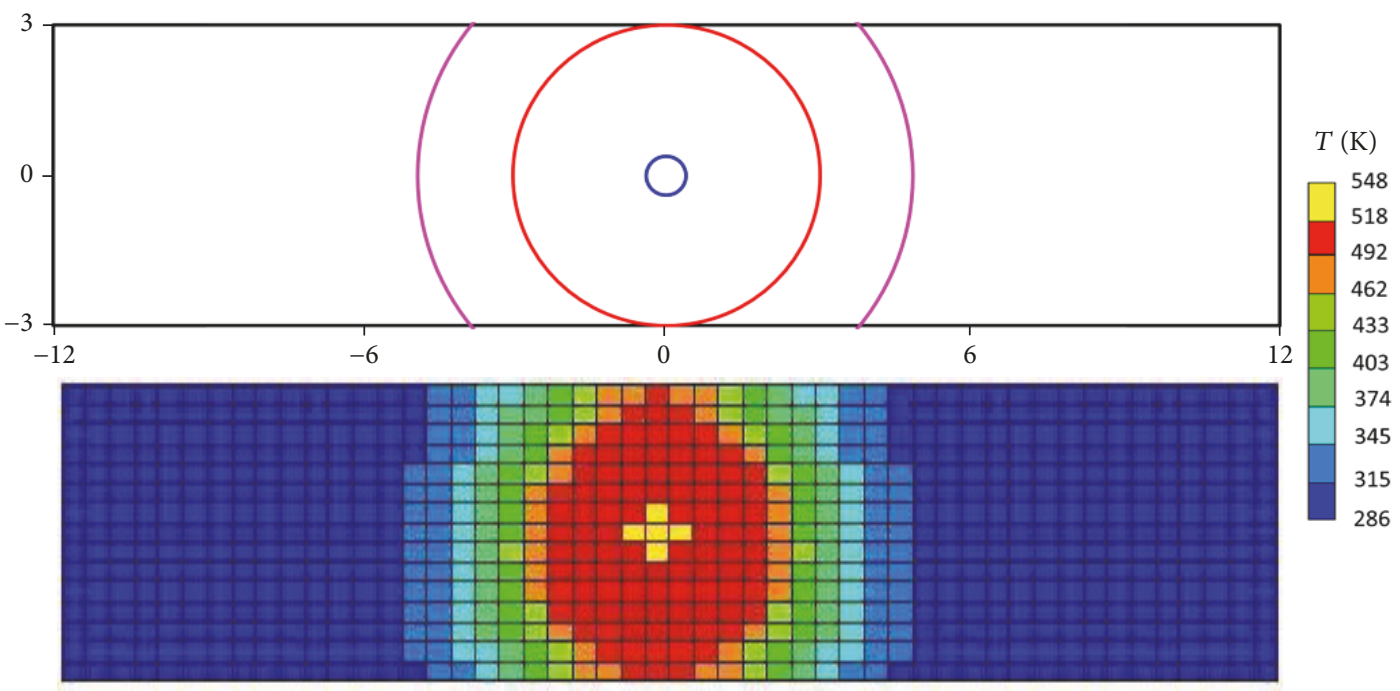

FIGURE 6: Comparisons of heat radius between the new model and CMG STARS perpendicular to the horizontal wellbore at length of 100m (pink line represents the frontier of hot fluid zone, red line represents the frontier of steam zone, and blue line represents superheated zone).

is later pumped. After the production of well decreased to a certain value, the steam is injected again and the well enters to the next cycle of stimulation. Figure 8 depicts the effect of the cycle of stimulation on heat radius. As can be seen from Figure 8, when the steam injection conditions (injection rate, superheated steam temperature, degree of superheat, and steam injection time) are all the same at different cycles, the radius of superheated zone, steam zone, and hot fluid zone increases with the cycle of stimulation. This is because there is remainder heat in the formation at the end of each cycle and therefore the heat radius is increased at next cycles.

\section{Conclusions}

In this paper, a new mathematical model for heat radius of cyclic superheated steam stimulation with horizontal wells is set up. The following conclusions can be derived as follows:

(1) The proposed mathematical model can be used to calculate the heat radius of cyclic superheated steam stimulation with horizontal wells. The heat radius calculated by the new model is highly in line with CMG STARS simulated result, which verifies the correctness of the new model.

(2) The heat radius of superheated zone, steam zone, and hot fluid zone all decreases with horizontal well length.

(3) The higher the degree of superheat, the longer the distance between the phase change point and the heel of the horizontal wellbore. Also, the radius of superheated zone, steam zone, and hot fluid zone 

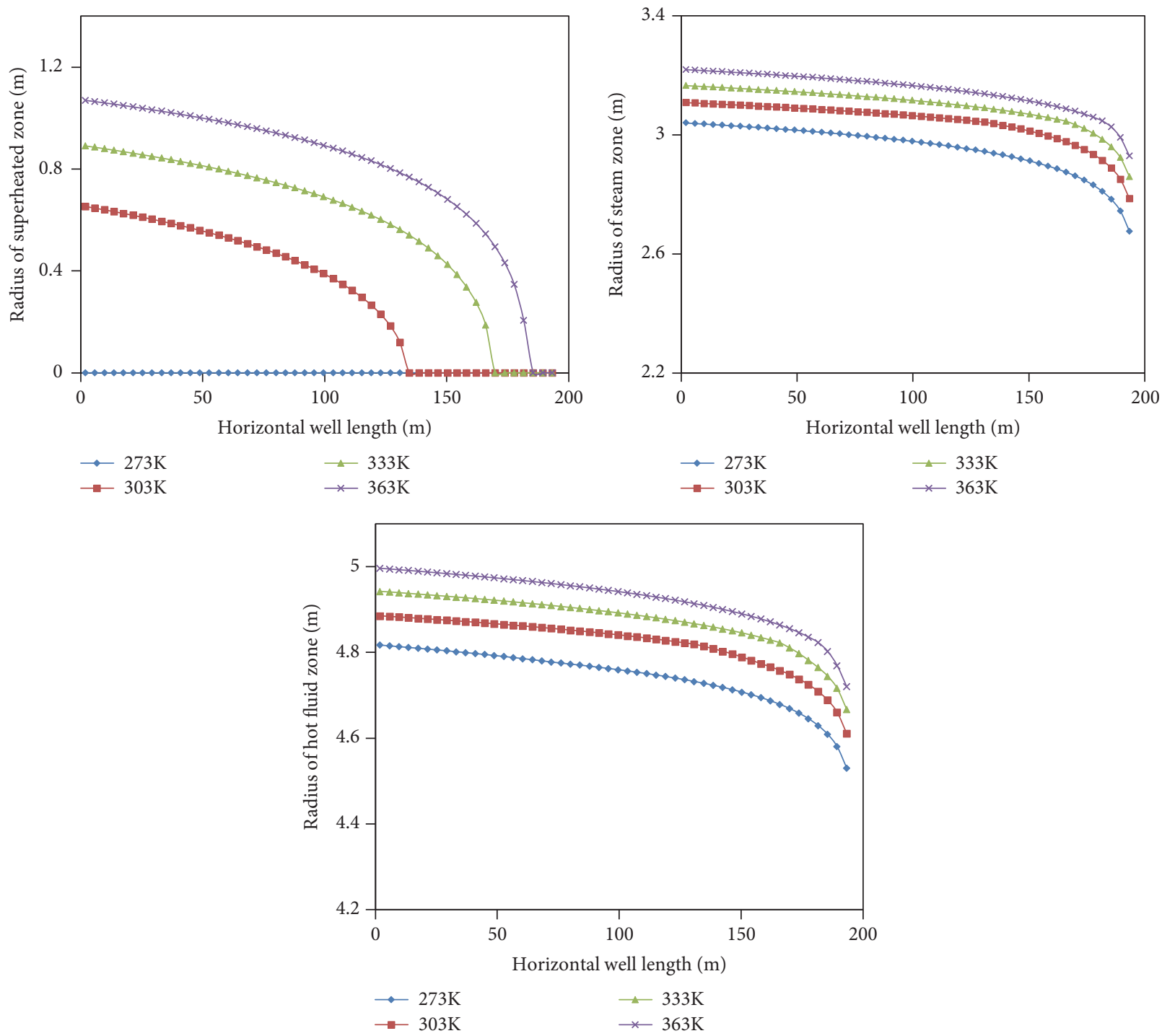

FIGURE 7: Effect of the degree of superheat on heat radius.

increases with the degree of superheat, but the value increases a little at steam zone and hot fluid zone.

(4) The radius of superheated zone, steam zone, and hot fluid zone increases with the cycle of stimulation.

\section{Nomenclature}

$A_{\mathrm{h} i}$ : The hot fluid zone area at the $i$-th segment, $\mathrm{m}^{2}$

$A_{\text {si }}$ : The steam zone area at the $i$-th segment, $\mathrm{m}^{2}$

$A_{\text {shi } i}$ : The superheated zone area at the $i$-th segment, $\mathrm{m}^{2}$

$A_{\mathrm{h} 1 i}$ : The hot fluid zone area at the $i$-th segment as the frontier of hot fluid zone reaches the boundary, $\mathrm{m}^{2}$

$A_{\mathrm{s} 1 i}$ : The steam zone area at the $i$-th segment as the frontier of steam zone reaches the boundary, $\mathrm{m}^{2}$
$B_{s i}:$ The contact area of boundary and steam zone at the $i$-th segment, $\mathrm{m}^{2}$

$B_{\mathrm{h} i}$ : The contact area of boundary and hot fluid zone at the $i$-th segment, $\mathrm{m}^{2}$

$d$ : The half thickness of the reservoir, $m$

$E_{\text {rshi }}$ : The previous cycle remainder heat of superheated zone at the $i$-th segment, $\mathrm{J} / \mathrm{s}$

$E_{\mathrm{rs} i}$ : The previous cycle remainder heat of steam zone at the $i$-th segment, $\mathrm{J} / \mathrm{s}$

$E_{\text {rwi }}$ : The previous cycle remainder heat of hot fluid zone at the $i$-th segment, J/s

$h_{s i}$ : The specific enthalpy of saturated steam at the $i$-th segment, $\mathrm{J} / \mathrm{kg}$

$h_{\text {shi }}$ : The specific enthalpy of superheated steam at the $i$-th segment, $\mathrm{J} / \mathrm{kg}$

$h_{\mathrm{w} i}$ : The specific enthalpy of saturated water at the $i$-th segment, $J / \mathrm{kg}$

$h_{\mathrm{wsi}}:$ The specific enthalpy of water at the steam temperature of the $i$-th segment, $\mathrm{J} / \mathrm{kg}$ 

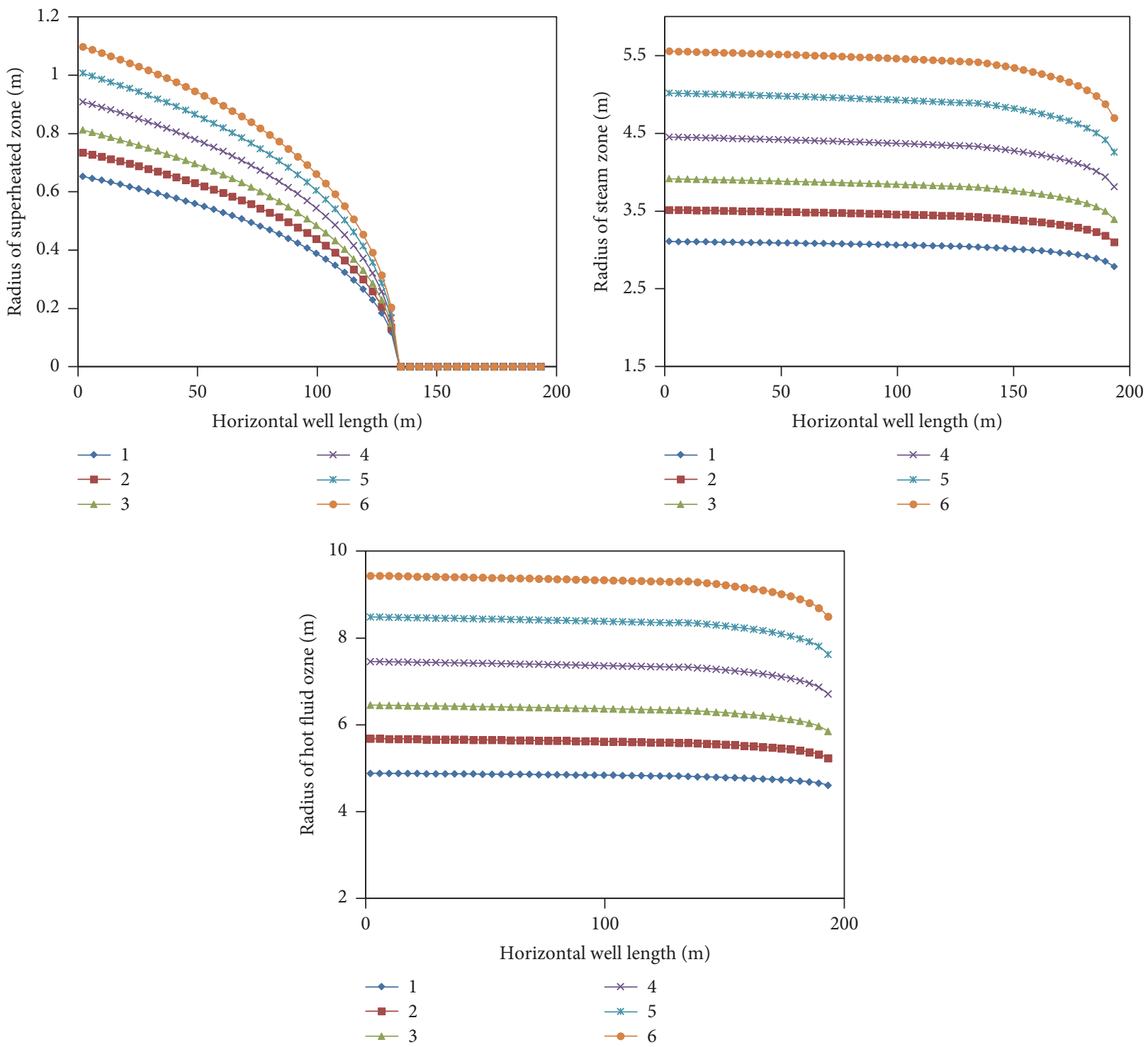

FIgURE 8: Effect of the cycle of stimulation on heat radius.

$h_{\text {wri }}$ : The specific enthalpy of water at the reservoir temperature of the $i$-th segment, $\mathrm{J} / \mathrm{kg}$

$H_{\text {shi }}$ : The superheated steam zone heat injection rate at the $i$-th segment, $\mathrm{J} / \mathrm{s}$

$H_{s i}$ : The steam zone heat injection rate at the $i$-th segment, $\mathrm{J} / \mathrm{s}$

$H_{\mathrm{w} i}$ : The hot fluid zone heat injection rate at the $i$-th segment, $\mathrm{J} / \mathrm{s}$

$I_{i}$ : The volumetric outflow rate at the $i$-th segment, $\mathrm{m}^{3} / \mathrm{s}$

$\Delta L:$ The length of segment, $\mathrm{m}$

$L_{\mathrm{v} i}$ : The steam latent heat at the i-th segment, $\mathrm{J} / \mathrm{kg}$

$M_{\mathrm{R}}$ : Reservoir heat capacity of, $\mathrm{J} /\left(\mathrm{m}^{3} \cdot \mathrm{K}\right)$

$r_{\mathrm{h} i}$ : Hot fluid zone radius at the $i$-th segment, $\mathrm{m}$

$r_{s i}: \quad$ Steam zone radius at the $i$-th segment, $\mathrm{m}$

$r_{\text {sh } i}$ : Superheated zone radius of at the $i$-th segment, $\mathrm{m}$ $t: \quad$ The injection time, $s$

$t_{\mathrm{cl} i}$ : The first critical time at the $i$-th segment, $\mathrm{s}$

$t_{\mathrm{c} 2 i}$ : The second critical time at the $i$-th segment, $\mathrm{s}$

$t_{\mathrm{c} 3 i}:$ The third critical time at the $i$-th segment, $\mathrm{s}$

$T_{\mathrm{r}}$ : The initial reservoir temperature, $\mathrm{K}$

$T_{s i}:$ The saturated steam temperature at the $i$-th segment, $\mathrm{K}$

$T_{\text {shi }}$ : The superheated steam temperature at the $i$-th segment, $\mathrm{K}$

$\overline{T_{\text {shi }}}$ : The superheated zone temperature, $\mathrm{K}$

$\overline{T_{\mathrm{h} i}}$ : The hot fluid zone temperature, $\mathrm{K}$.

\section{Greek Letters}

$\alpha_{\mathrm{s}}$ : Thermal diffusivity of boundary, $\mathrm{m}^{2} / \mathrm{d}$

$\lambda_{s}$ : Thermal conduction coefficient of boundary, $\mathrm{W} /(\mathrm{m} \cdot \mathrm{K})$

$\rho_{i}$ : The steam density at the $i$-th segment, $\mathrm{kg} / \mathrm{m}^{3}$ 
$\delta$ : The instant at which the boundary becomes exposed to the hot fluid, s.

Subscripts
$i$ : The $i$-th segment.

\section{Data Availability}

The data used to support the findings of this study are available from the corresponding author upon request.

\section{Conflicts of Interest}

The authors declare that they have no conflicts of interest.

\section{Acknowledgments}

This work was supported by the Key National Projects (2017ZX05030).

\section{References}

[1] M. B. Roger, Thermal Recovery of Oil and Bitumen, Prentice Hall, NJ, USA, 1th edition, 1991.

[2] W. Z. Liu, Steam Injection for Thermal Recovery of Heavy Oils, Petroleum industry press, Beijing, China, 1th edition, 1997.

[3] H. Q. Liu, Y. P. Fan, D. W. Zhao et al., Principles and Methods of Thermal Oil Recovery Technology, China University of Petroleum Press, Dongying, China, 1th edition, 2008.

[4] M. F. Chen, Z. X. Lang, and X. G. Mo, "Study on rational threshold of cyclic steam stimulation with horizontal well in extra-heavy oil reservoir," Special Oil and Gas Reservoir, vol. 9, no. 2, pp. 37-41, 2002.

[5] S. Luo and A. L. Baker, "Optimizing horizontal-well steamstimulation strategy for heavy-oil development," in Proceedings of the SPE Eastern Regional Meeting, Canton, Oh, USA, 2006.

[6] L. Cosentino, G. Spotti, J. Gonzalez, Y. Araujo, and J. Herrera, "Cyclic steam injection on parallel horizontal wells: geostatistical description, thermal simulation and field experience," in Proceedings of the SPE Annual Technical Conference and Exhibition, New Orleans, La, USA, 1998.

[7] M. Mirza, P. Aditama, M. Al Raqmi, and Z. Anwar, "Horizontal well steam stimulation: a pilot test in southern oman," in Proceedings of the SPE EOR Conference at Oil and Gas West Asia, Muscat, Oman, 2014.

[8] Z. Liguo, Z. Shoujun, W. Fei et al., "Improve heavy oil recovery by separated-zones horizontal well steam stimulation," in Proceedings of the Canadian Unconventional resources International petroleum conference, Calgary, Canada, 2010.

[9] G. Pingyuan, D. Yongxin, and L. Guocheng, "Uniform steam injection technology used in thermal horizontal wells," in Proceedings of the in. proceedings of the CPS/SPE international oil gas conference and exhibition, p. 10, Beijing, China, SPE, 2010.

[10] Z. Tiyao, C. Linsong, L. Chunlan et al., "Experiment of aquathermalysis reaction between heavy oil and over-heated steam," Journal of Southwest Petroleum University (Science \& Technology Edition), vol. 31, no. 6, pp. 89-92, 2009.

[11] L. Chuntao, Q. Genbao, W. Shuhong et al., "Superheated steam quality and its application to heavy oil reservoir development by steam stimulation-an example from upsalt heavy oil reservoir in Kenjiyake field," Xinjiang Petroleum Geology, vol. 29, no. 4, pp. 495-497, 2008.

[12] G. Qunli, "Research and experiment on the shallow thin layer super heavy oil superheated steam drive developmenttake Louzi 27well area as example," Petroleum Geology and Engineering, vol. 25, no. 2, pp. 76-78, 2011.

[13] L. Xing, H. Zheng, and F. Yongtao, "Production limit and injector-producer parameter optimization of superheated steam soaks," Journal of Oil and Gas Technology, vol. 34, no. 6, pp. 148-151, 2012.

[14] H. Gu, L. Cheng, S. Huang, B. Bo, Y. Zhou, and Z. Xu, “Thermophysical properties estimation and performance analysis of superheated-steam injection in horizontal wells considering phase change," Energy Conversion and Management, vol. 99, pp. 119-131, 2015.

[15] W. J. Marx and R. H. Langenheim, "Reservoir heating by hot fluid injection petroleum transactions," AIME, pp. 312-315, 1959.

[16] B. Willman, V. Valleroy, G. Runberg, A. Cornelius, and L. Powers, "Laboratory studies of oil recovery by steam injection," Journal of Petroleum Technology, vol. 13, no. 7, pp. 681-696, 1961.

[17] L. Chunlan and C. Linsong, "A method for calculation heating radius in steam stimulation of viscous oil reservoir," Xin Jiang Petroleum Geology, vol. 19, no. 3, pp. 247-249, 1998.

[18] L. Chunlan and Y. Bingxiu, "Non-isothermal productivity predicting model of heavy crude oil exploited with huff and puff," Oil Drilling \& Production Technology, vol. 25, no. 5, pp. 89-90, 2003.

[19] T. Zhou, L. Cheng, C. He, Z. Pang, and F. Zhou, "Calculation model of on-way parameters and heating radius in the superheated steam injection wellbore," Shiyou Kantan Yu Kaifa/Petroleum Exploration and Development, vol. 37, no. 1, pp. 83-88, 2010.

[20] L. Lingbin, P. Tingting, Q. Yun et al., "A calculation method for heat loss considering steam overlap in steam flooding," Journal of Northwest University (Natural Science Edition), vol. 44, no. 1, pp. 104-110, 2014.

[21] L. Lai, T. Pan, W. Hu, X. Song, and Q. Ran, "A calculation model for thermal efficiency based on steam overlap in heavy oil steam flooding," Chongqing Daxue Xuebao/Journal of Chongqing University, vol. 37, no. 5, pp. 90-97, 2014.

[22] X.-F. Ni and L.-S. Cheng, "Calculating models for heating area of horizontal wellbore in steam stimulation," Shiyou Kantan $\mathrm{Yu}$ Kaifa/Petroleum Exploration and Development, vol. 32, no. 5, pp. 108-112, 2005.

[23] C. Liu, L. Cheng, Y. Liu, and Z. Pang, "Calculating models for heating radius of cyclic steam stimulation and formation parameters in horizontal well after soaking," Shiyou Xuebao/Acta Petrolei Sinica, vol. 29, no. 1, pp. 101-105, 2008.

[24] C. He, L. Mu, A. Xu, and S. Fang, "A new model of steam soaking heating radius and productivity prediction for heavy oil reservoirs," Shiyou Xuebao/Acta Petrolei Sinica, vol. 36, no. 12, pp. 1564-1570, 2015.

[25] C. He, L. Mu, Z. Fan et al., "An improved steam injection model with the consideration of steam override," Oil \& Gas Science and Technology-Revue d'IFP Energies nouvelles, vol. 72, no. 1, Article ID 6, pp. 1-14, 2017.

[26] A. Xu, L. Mu, Z. Fan et al., "Mechanism of heavy oil recovery by cyclic superheated steam stimulation," Journal of Petroleum Science and Engineering, vol. 111, pp. 197-207, 2013. 
[27] W. Xianghong, X. Anzhu, and F. Hailiang, "An integrated evaluation on factors affecting the performance of superheated steam huff and puff in heavy oil reservoirs," Petroleum Exploration and Development, vol. 37, no. 5, pp. 608-613, 2010.

[28] X. Anzhu, W. Xianghong, F. Zifei et al., "Selection of superheated steam flooding in Kenkiyak heavy oil reservoirs," Science \& technology review, vol. 27, no. 6, pp. 29-33, 2009.

[29] H. Congge, X. Anzhu, F. Zifei et al., "New calculation model of the heated radius for the superheated steam injection in heavy oil reservoirs," Petroleum Geology and Oilfield Development in Daqing, vol. 36, no. 2, pp. 117-122, 2017.

[30] Z. Fan, C. He, and A. Xu, "Calculation model for on-way parameters of horizontal wellbore in the superheated steam injection," Shiyou Kantan Yu Kaifa/Petroleum Exploration and Development, vol. 43, no. 5, pp. 733-739, 2016.

[31] H. S. Carslaw and J. C. Jaeger, Conduction of Heat in Solids, Oxford University Press, New York, NY, USA, 1986. 


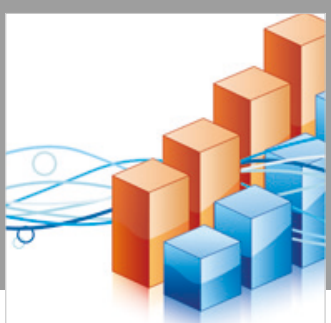

Advances in

Operations Research

\section{-n-m}
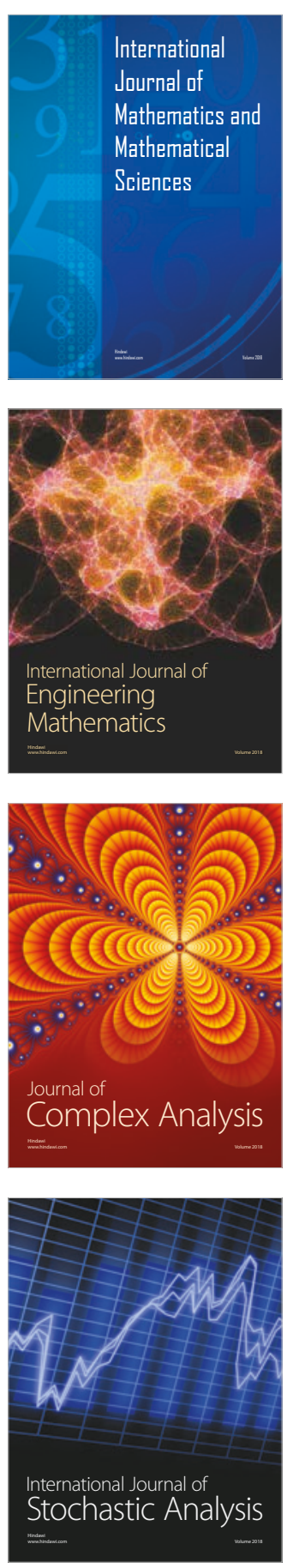
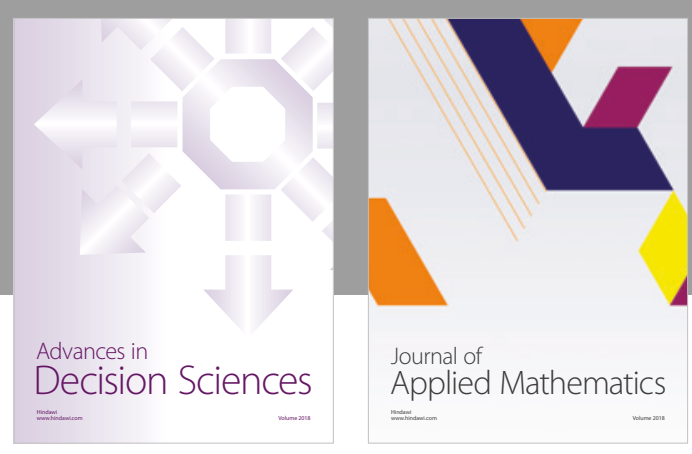

Journal of

Applied Mathematics
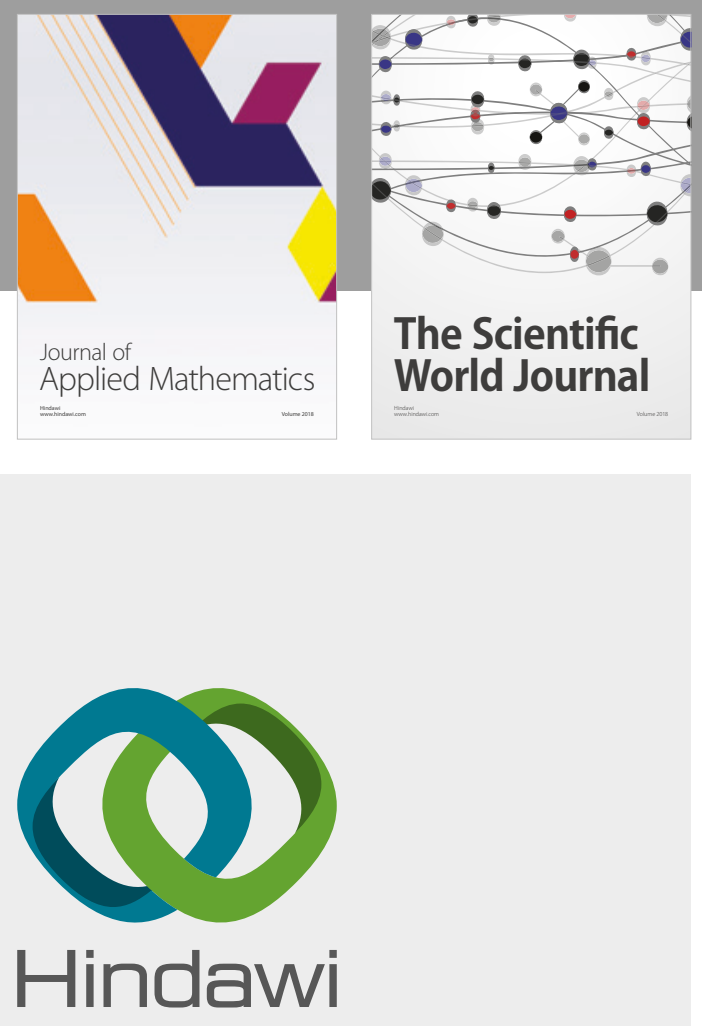

Submit your manuscripts at

www.hindawi.com

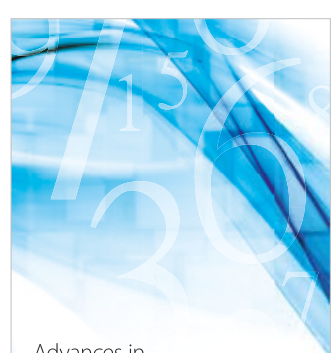

Advances in
Numerical Analysis
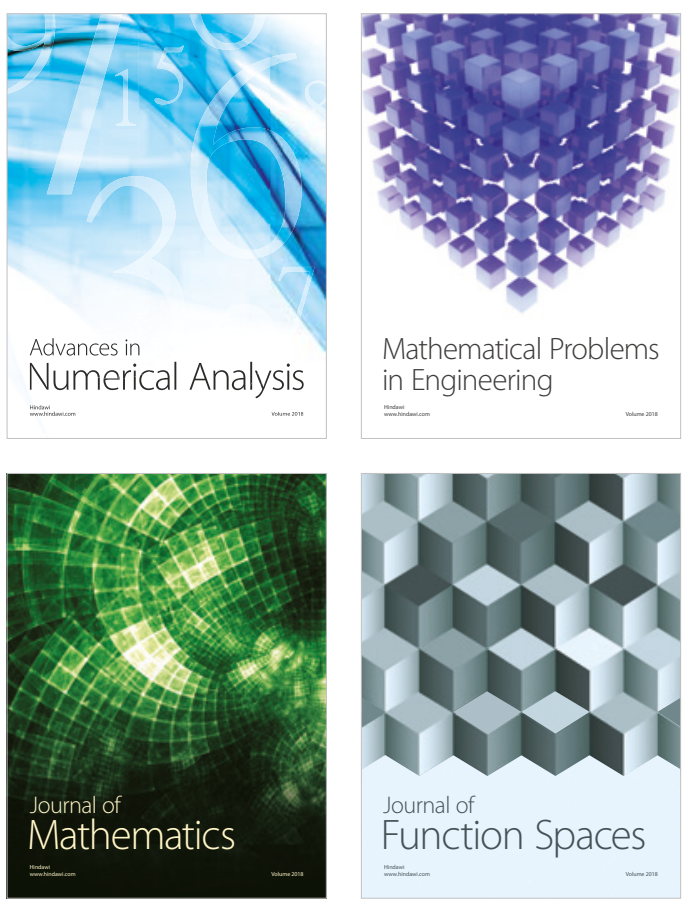

Mathematical Problems in Engineering

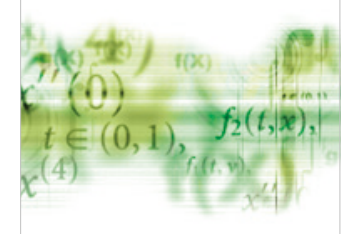

International Journal of

Differential Equations

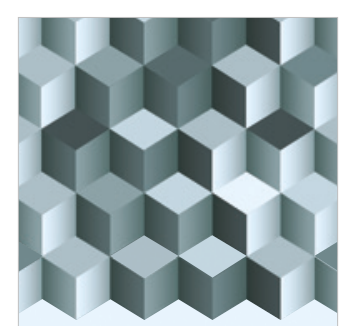

Journal of

Function Spaces

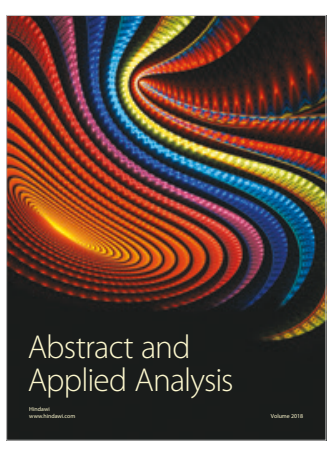

The Scientific

World Journal

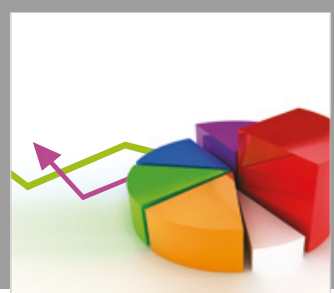

Journal of

Probability and Statistics
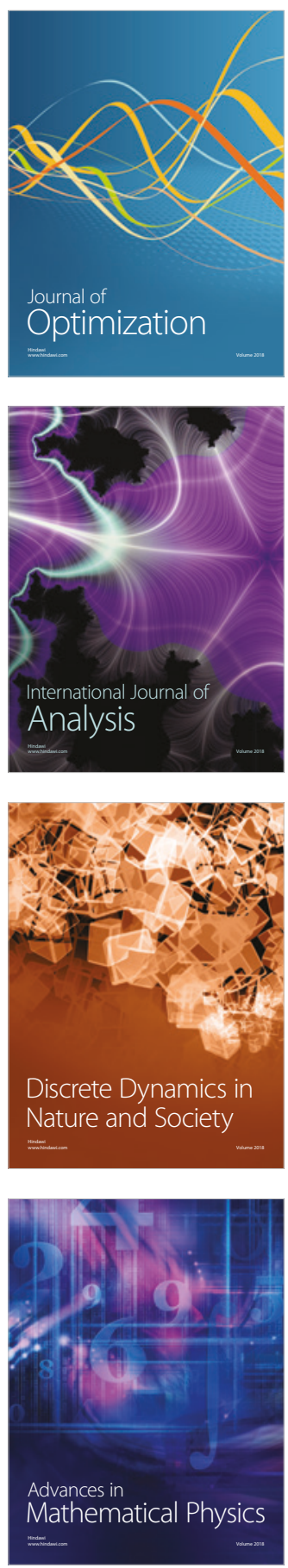